\title{
Social position and mortality from respiratory diseases in males and females
}

\author{
E. Prescott*, N. Godtfredsen*, J. Vestbo", M. Osler"
}

Social position and mortality from respiratory diseases in males and females. E. Prescott, N. Godtfredsen, J. Vestbo, M. Osler. (C) ERS Journals Ltd 2003.

ABSTRACT: Although social differences in respiratory diseases are considerable, few studies have focused on this disease entity using mortality as an outcome. Does mortality from respiratory disease, including chronic obstructive pulmonary disease (COPD) differ with social position measured by education, income, housing and employment grade?

The study population consisted of 26,392 males and females from pooling of two population studies in the Copenhagen area. Data was linked with information from social registers in Statistics Denmark. The relationship between socioeconomic factors and risk of death from respiratory disease and COPD was assessed with an average duration of follow-up of 12 yrs.

Education was strongly associated with respiratory mortality in both sexes. The association was stronger in later birth cohorts comparing the highest level of education ( $>11$ yrs) with the lowest ( $<8 \mathrm{yrs})$. Although smoking rates were inversely associated with the level of education, the social gradient was not affected by adjustment for smoking. In males, but not in females, there was an additional effect of other indicators of social position, i.e. employment grade (white collar versus blue collar), household income, housing conditions (less than one person per room versus more), and cohabitation (cohabiting versus living alone). Similar results were found for mortality from COPD.

The results confirm the existence of a strong social gradient in respiratory mortality and chronic obstructive pulmonary disease, which is independent of smoking and is stronger in males. Social disadvantage is a potentially avoidable cause of death from respiratory disease and further research is needed to explain the excess risk in the socioeconomically disadvantaged.

Eur Respir J 2003; 21: 821-826.
*Copenhagen Centre for Prospective Population Studies, Danish Epidemiology Science Centre at the Institute of Preventive Medicine, University of Copenhagen, ${ }^{\#}$ Dept of Respiratory Medicine, Hvidovre Hospital and ${ }^{\top}$ Dept of Social Medicine, Institute of Public Health, University of Copenhagen, Copenhagen, Denmark.

Correspondence: E. Prescott, Institute of Preventive Medicine, Kommunehospitalet DK1399, Copenhagen, Denmark.

Fax: 4533913244

E-mail: eva.prescott@dadlnet.dk

Keywords: Chronic obstructive pulmonary disease

education

epidemiology

follow-up study

socioeconomic status

Received: June 32002

Accepted after revision: January 112003

This study was supported by grants from The Danish Ministry of Health and The National Union against Lung Diseases.
Social position is known to be associated with mortality from a number of diseases and studies indicate that the social inequalities in health are increasing [1]. Although there are strong indicators that the social differences in respiratory diseases are considerable [2, 3], few studies have focused on this disease entity using mortality as an outcome. Social gradient in smoking and occupational exposure to airborne pollutants explains only some of the association, and further exploration is called for.

Studying the association between social position and morbidity is complex because social position includes several dimensions. The choice of which measures to use depends on theories about pathways between social conditions and disease outcome. These pathways are not mutually exclusive and the use of several indicators of social position in studies of social inequalities in health, have been recommended.

In a previous study, the authors have shown that income and education are associated with lung function independently of smoking in both females and males. Subsequent risk of admission to hospital for chronic obstructive pulmonary disease (COPD) was three-fold higher for the lowest socioeconomic group compared with the highest [4]. The present study explores the association between various measures of social status and mortality from respiratory disease and from COPD in 26,392 randomly sampled males and females followed prospectively for a mean of $12 \mathrm{yrs}$.

\begin{abstract}
Methods
Study population

The present study was based on pooled data from two longitudinal population studies conducted in the Copenhagen area; The Copenhagen City Heart Study (CCHS) and The Glostrup Population Studies (GPS), both of which have been described in detail previously $[5,6]$.

Briefly, the CCHS population comprised 14,119 randomly selected males and females aged $\geqslant 20 \mathrm{yrs}$ from a defined area of central Copenhagen who were first examined in 1976/ 1978 (response rate 72). In 1981-1983 and 1992-1993, 1,560 and 2,360 new subjects, respectively, were included. Between 1964-1992, the GPS examined 10,092 subjects from different birth cohorts in selected suburbs of Copenhagen with equal distribution of males and females (response rates 69-92). The combined study population consisted of 28,131 subjects attending examinations between 1964-1992.

The study population was linked to the registers of socioeconomic information in Statistics Denmark using the person identification number as a key. Information on housing, income, and occupation were obtained for study participants and cohabiting adults for the years 1980, 1985, 1990, and 1995, and each participant was linked with information from the year closest before their baseline examination.
\end{abstract}


Information on gross annual income was obtained for each study participant and their cohabitant. The gross income comprises all income types subject to income taxation (wages and salaries, all types of benefits and pensions, net surplus or deficit, interest received and shared dividends). Household income was calculated as the sum of individual and cohabitants gross income. Income was corrected for inflation since 1980 using the price index from Statistics Denmark.

Information on housing was obtained from the register of Building and Dwelling statistics. For this study, the authors used availability of central heating (yes/no) as an indicator of quality and dampness of housing, and the number of persons per room as an indicator of crowding. Very few had less than one room per person and the covariate was dichotomised with the cut-off point $\geqslant 1$ room per person. Employment grade was grouped in five categories: managers (including selfemployed and assistant wives), salaried employees, skilled labour, unskilled labour, and persons outside the workforce. For some analyses, employment grade was dichotomised into white collar and blue collar. Level of education was selfreported and divided into three categories: $<8$ yrs of schooling, 8-11 yrs, and $>11$ yrs. These cut-off points were chosen because until 1972 compulsory school was 7 yrs. Since then it has been 9 yrs. Twelve years of schooling is equivalent to completion of high school.

The main confounder was smoking. All subjects were divided into the following six categories according to baseline smoking status: never-smokers, exsmokers, noninhaling smoker, current light (1-14 g), current medium (15-24 g), and current heavy smokers ( $>24 \mathrm{~g}$ of tobacco per day). Duration of smoking for current smokers was also available. Analyses were adjusted for cohort of origin (CCHS and GPS).

\section{Follow-up}

Subjects were followed for cause specific mortality until January 1, 1997. Causes of death were obtained from official death certificates coded at the National Board of Health using the eighth and tenth revision of the International Classification of Diseases (ICD). For these analyses, death from respiratory diseases was used (ICD-8 codes 11-19, 466, $490-493,471-486,460-464$ and 502-519, ICD-10 codes A150-A169, J429-J449, J459-J469, J139-J189 and J690J984). COPD (ICD-8 466 and 490-492, ICD-10 J429-J449) caused $\sim 60 \%$ of respiratory deaths and another $20 \%$ were caused by pneumonia (ICD-8 471-486, ICD-10 J139-J189). Separate analyses of deaths from COPD were also performed.

\section{Statistical methods}

The association between risk factors and mortality was analysed using Cox's proportional hazards regression models with age as the underlying time scale. The age at study inclusion or age at the year of register information, whichever was highest, was used as the age of entry in the analyses. The continuous variables were evaluated for linearity using likelihood ratio tests. The proportional hazards assumption was evaluated for all variables by comparing $-\ln (-\ln$ (survival)) curves over the different categories of the variables being investigated versus $\ln ($ analysis time $) \times(\log -\log$ plots $)$, and by tests based on the generalisation of GRAMBSCH and THERNAU [7]. Tests for interaction were performed using the likelihood ratio test. Initial analyses were done for each sex separately and only if results did not differ were they reported for the pooled data.

\section{Results}

Information from Statistics Denmark was obtained for 26,928 participants. The remaining 1,203 subjects were lost due to death before $1980(n=1080)$, emigration $(n=22)$, or no registered address in Denmark in $1980(\mathrm{n}=101)$. A further 536 did not report their level of education, leaving 26,392 (13,992 females and 12,400 males) for analyses. During follow-up there were 512 deaths from respiratory disease (226 females, 286 males); 314 were from COPD. Baseline data by level of education is shown in table 1. Subjects, with higher levels of education tended to be younger, male, nonsmokers, and from the CCHS

Results from univariate analyses of each indicator of social position on risk of mortality from pulmonary disease are given in table 2 . In females, only education was significantly associated with mortality. Since females are more often supported economically by their spouse, individual income was stratified by whether persons were living alone, but this did not alter the results (not shown). In males, education, housing, employment grade, and income were all significantly associated with respiratory mortality. Education and central heating were the only socioeconomic measures with similar strength of association in males and females.

Associations were explored further with adjustment for

Table 1.-Baseline data of the 26392 subjects in the Copenhagen Centre for Population Studies by level of education

\begin{tabular}{|c|c|c|c|c|}
\hline & \multicolumn{3}{|c|}{ Level of education } & \multirow[t]{2}{*}{ p-value ${ }^{\#}$} \\
\hline & $<8$ yrs & $8-11$ yrs & $>11 \mathrm{yrs}$ & \\
\hline Subjects $n$ & 10911 & 11672 & 3809 & \\
\hline Age yrs & $57.9 \pm 11.2$ & $49.7 \pm 13.2$ & $42.7 \pm 14.2$ & 0.001 \\
\hline Females & $5858(53.7)$ & $6292(53.9)$ & $1842(48.4)$ & 0.001 \\
\hline Current smokers & $6968(64.1)$ & 6864 (58.9) & 1839 (48.4) & 0.001 \\
\hline Heavy smokers & $3902(35.9)$ & $4001(34.3)$ & $976(25.6)$ & 0.001 \\
\hline$\geqslant 1$ Room per person & $9969(93.3)$ & $10615(92.6)$ & $3460(93.1)$ & 0.11 \\
\hline White collar & $2704(24.8)$ & $6339(35.4)$ & $2691(70.7)$ & 0.001 \\
\hline Personal income $\times 1000 \mathrm{DKR}$ & $145 \pm 209$ & $195 \pm 162$ & $237 \pm 216$ & 0.001 \\
\hline Cohabitating & $7050(64.6)$ & $7867(67.4)$ & $2220(58.3)$ & 0.001 \\
\hline CCHS & $7290(66.8)$ & $6924(59.3)$ & $2993(78.6)$ & 0.001 \\
\hline Born after 1920 & 7019 (64.3) & $9561(81.9)$ & $3336(87.6)$ & 0.001 \\
\hline
\end{tabular}

Data are presented as mean \pm SD or $\mathrm{n}(\%)$ unless otherwise stated. CCHS: Copenhagen City Heart Study. ${ }^{\#}$ : from Chi-squared or analysis of variance. 
Table 2. - Crude relative risk (RR) of death from respiratory disease by indices of education, housing, employment grade, income, and family type in 13992 females and 12400 males in the Copenhagen Centre for Prospective Population Studies

\begin{tabular}{|c|c|c|}
\hline & Females & Males \\
\hline \multicolumn{3}{|l|}{ Education } \\
\hline$<8$ yrs & 1 & 1 \\
\hline $8-11 \mathrm{yrs}$ & $0.59(0.44-0.79)$ & $0.53(0.40-0.70)$ \\
\hline$>11$ yrs & $0.42(0.20-0.89)$ & $0.52(0.33-0.82)$ \\
\hline \multicolumn{3}{|l|}{ Housing } \\
\hline No central heating & 1 & 1 \\
\hline Central heating & $0.75(0.56-1.02)^{\S}$ & $0.73(0.56-0.94)$ \\
\hline$<1$ Room per person & 1 & 1 \\
\hline$\geqslant 1$ Room per person & $1.16(0.43-3.12)$ & $0.52(0.32-0.86)$ \\
\hline \multicolumn{3}{|l|}{ Employment grade } \\
\hline Managers & 1 & 1 \\
\hline Salaried employees & $1.13(0.55-2.29)$ & $1.17(0.66-2.08)$ \\
\hline Skilled labour & $1.82(0.24-14.15)$ & $1.53(0.91-2.59)$ \\
\hline Unskilled labour & $1.53(0.76-3.07)$ & $2.33(1.52-3.53)$ \\
\hline Outside work-force & $1.76(0.95-3.29)$ & $2.37(1.67-3.37)$ \\
\hline Blue collar & 1 & 1 \\
\hline White collar $\#$ & $0.71(0.43-1.15)$ & $0.52(0.37-0.74)$ \\
\hline Outside workforce & $1.15(0.75-1.75)$ & $1.19(0.86-1.64)$ \\
\hline \multicolumn{3}{|l|}{ Gross income } \\
\hline \multicolumn{3}{|l|}{ Personal income } \\
\hline Per $50000 \mathrm{DKR}^{\top}$ & $0.94(0.86-1.03)^{f}$ & $0.81(0.76-0.87)$ \\
\hline Household income $^{+}$ & & \\
\hline Per 100000 DKR & $1.00(0.85-1.17)$ & $0.96(0.76-0.97)$ \\
\hline \multicolumn{3}{|l|}{ Family type } \\
\hline Living alone & 1 & 1 \\
\hline Cohabitating & $0.97(0.74-1.28)$ & $0.60(0.47-0.77)$ \\
\hline
\end{tabular}

Data are presented as RR (95\% confidence interval). ${ }^{*}$ : bluecollar comprised skilled and unskilled labour; white-collar comprised managers and salaried employees including selfemployed and assistant wives; ${ }^{\top}: 8 \mathrm{DKR}$ is $\sim € 1$; $^{+}$: subjects living alone excluded; ${ }^{\S}$ : after adjustment for education, $\mathrm{p}=0.15$; ${ }^{f}$ : after adjustment for education, $\mathrm{p}=0.88$. Results from Cox regression analyses adjusted for age and cohort of origin.

smoking and cohabitation yielding the results given in table 3 . Among females, only education was significantly associated with respiratory mortality. Among males, only central heating did not retain statistical significance and was omitted from the model. Although associations were attenuated, they all retained statistical significance after adjustment for smoking. Relative risks (RRs) associated with smoking were higher in females than in males.

Education was the only socioeconomic measure with similar strength of association in males and females and was
Table 3. - Adjusted relative risk (RR) of death from respiratory disease by indices of education, housing, employment grade, income, and family type in 13992 females and 12400 males in the Copenhagen Centre for Prospective Population Studies

\begin{tabular}{|c|c|c|}
\hline & Females & Males \\
\hline \multicolumn{3}{|l|}{ Education $^{\#}$} \\
\hline$<8$ yrs & Ref & Ref \\
\hline$\geqslant 8$ yrs & $0.63(0.47-0.86)$ & $0.72(0.55-0.95)$ \\
\hline \multicolumn{3}{|l|}{ Housing } \\
\hline$<1$ Room per person & Ref & Ref \\
\hline$\geqslant 1$ Room per person & $0.99(0.37-2.68)$ & $0.51(0.31-0.84)$ \\
\hline \multicolumn{3}{|l|}{ Employment grade } \\
\hline Blue collar & Ref & Ref \\
\hline White collar & $0.94(0.57-1.57)$ & $0.68(0.47-0.99)$ \\
\hline Outside workforce & $1.53(0.94-2.48)$ & $0.94(0.63-1.39)$ \\
\hline \multicolumn{3}{|l|}{ Gross income } \\
\hline \multicolumn{3}{|l|}{ Personal income } \\
\hline Per $50000 \mathrm{DKR}^{+}$ & $1.04(0.91-1.19)$ & $0.88(0.79-0.97)$ \\
\hline \multicolumn{3}{|l|}{ Family type } \\
\hline Living alone & Ref & Ref \\
\hline Cohabitating & $1.07(0.79-1.45)$ & $0.67(0.52-0.87)$ \\
\hline \multicolumn{3}{|l|}{ Smoking } \\
\hline Never-smoker & Ref & Ref \\
\hline Exsmoker & $2.96(1.80-4.87)$ & $1.39(0.77-2.51)$ \\
\hline \multicolumn{3}{|l|}{ Current smoker } \\
\hline Noninhaler & $2.01(1.23-3.27)$ & $1.12(0.61-2.07)$ \\
\hline $1-14 \mathrm{~g} \cdot \mathrm{day}^{-1}$ & $5.21(3.23-8.41)$ & $2.42(1.34-4.37)$ \\
\hline $15-24 \mathrm{~g} \cdot \mathrm{day}^{-1}$ & $10.67(6.62-17.23)$ & $3.19(1.81-5.64)$ \\
\hline$>24 \mathrm{~g} \cdot \mathrm{day}^{-1}$ & $23.71(12.30-45.73)$ & $4.68(2.52-8.69)$ \\
\hline
\end{tabular}

Data are presented as RR (95\% confidence interval). Ref: reference value. \#: education groups $8-11$ yrs and $>11$ yrs pooled because of similar RRs; ${ }^{\text {: }}$ blue collar comprised skilled and unskilled labour; white-collar comprised managers and salaried employees including self-employed and assistant wives; ${ }^{+}$: $8 \mathrm{DKR}$ is $\sim € 1$. Results from Cox regression analyses adjusted for age, cohort of origin and covariates in the table.

explored further. When testing model assumptions, the authors found a lack of proportionality for hazard associated with education in females. This could be modelled by agespecific risk estimates for education, but the best model found included an interaction term between education and birth cohort. Initially, the effect of birth cohort was explored in three categories using cut-off points in 1920 and 1940. Since no additional effect of birth cohort was found for the group born after 1940, results are given for subjects born before and after 1920. Associations were strongest in the younger birth cohorts where a graded association was seen (table 4). The difference between educational levels was not significant

Table 4.- Relative risk (RR) of death from respiratory disease by level of education and birth cohort in the Copenhagen Centre for Prospective Population Studies. Results from Cox regression analyses

\begin{tabular}{|c|c|c|c|}
\hline Education & Females ${ }^{\#}$ & Males ${ }^{\#}$ & $\begin{array}{l}\text { Pooled, } \\
\text { adjusted }\end{array}$ \\
\hline \multicolumn{4}{|c|}{ Born before $1920^{+}$} \\
\hline$<8$ yrs & 1 & 1 & 1 \\
\hline $8-11 \mathrm{yrs}$ & $0.74(0.50-1.08)$ & $0.62(0.44-0.88)$ & $0.67(0.52-0.87)$ \\
\hline$>11$ yrs & $0.71(0.31-1.63)$ & $0.65(0.38-1.11)$ & $0.74(0.47-1.16)$ \\
\hline \multicolumn{4}{|c|}{ Born 1920 or later $^{+}$} \\
\hline$<8$ yrs & 1 & 1 & 1 \\
\hline $8-11$ yrs & $0.42(0.27-0.68)$ & $0.44(0.28-0.69)$ & $0.45(0.32-0.62)$ \\
\hline$>11 \mathrm{yrs}$ & $0.11(0.02-0.81)$ & $0.32(0.13-0.80)$ & $0.26(0.11-0.58)$ \\
\hline
\end{tabular}

Data are presented as RR (95\% confidence interval). ${ }^{\#}$ : adjusted for age and cohort of origin; ${ }^{\top}$ : males and females pooled, adjusted for age, sex, cohort of origin and smoking (six categories); ${ }^{+}$: Chi-squared test for interaction between birth cohort and level of education (females $\mathrm{p}=0.04$; males $\mathrm{p}=0.25$; pooled, adjusted $\mathrm{p}=0.05$ ). 
among females in the older birth cohorts, perhaps because relatively few females in these birth cohorts had higher levels of education. In males, there was also a tendency for larger differences in the younger birth cohorts but the difference between birth cohorts was not significant (table 3 ).

Risk estimates were similar in males and females in both birth cohorts. In order to increase study power further, multivariate analyses were conducted on pooled data after formally testing for interactions between sex and other covariates and finding no indications of this. As expected, smoking was strongly associated with mortality from respiratory disease. RRs (95\% confidence intervals) associated with smoking were $1.77(1.22-2.58)$ in noninhaling smokers, $2.36(1.63-3.41)$ in exsmokers and $9.53(6.21-14.62)$ in heavy smokers who inhaled with intermediary risks in inhaling light and medium smokers. Adjustment for smoking did not affect estimated risks associated with education. Analyses using COPD deaths as the end-point gave similar results; in the younger birth cohorts RRs for the intermediary and highest level of education were $0.42(0.28-0.61)$ and $0.05(0.01-0.39)$, respectively. In the older birth cohorts, they were 0.49 (0.34-0.71) and $0.61(0.34-1.11)$, respectively.

Changes in smoking habits during follow-up could cause residual confounding by smoking if the more educated smokers have higher quit-rates. Analysis of never-smokers only was not feasible due to the limited number of end-points in this group. A separate analysis of never- and exsmokers, however, yielded results similar to the ones given in table 4. In addition, analyses including only the first 10 yrs of follow-up, and thus, limiting possible changes in smoking habits gave results similar to the ones presented. After adjustment for smoking, RRs for the intermediary and highest level of education in the younger birth cohorts were $0.36(0.18-0.73)$ and $0.23(0.03-1.65)$, respectively, and $0.73(0.46-1.16)$ and $0.74(0.32-1.71)$ in the older birth cohorts, respectively.

\section{Discussion}

This study confirms that level of education, as an indicator of social position is a predictor of respiratory mortality independently of smoking. Subjects with the lowest level of education had more than twice the risk of subjects with the highest level of education in both males and females. In males, but not in females, there was an additional effect of other indicators of social position, namely housing conditions, employment grade, income and cohabitation.

The difference in impact of education with birth cohort in females may be related to the increase in the average length of schooling. Of the subjects, $60 \%$ born before 1920 had $<8$ yrs of formal schooling versus $35 \%$ of those born after 1920 . The large group in the older cohorts with a low level of school education is likely to have more variation in adult education, and this could cause the underestimation of the health gradient associated with education in these birth cohorts. The difference with birth cohort may also reflect an increased social gradient in disease as reported in other studies [1]. Nonresponse and mortality are both higher among the deprived. This may introduce a bias, which, although likely to diminish during the follow-up period, has been shown to lead to underestimation of social class differences [8]. Finally, it is possible that selective loss of low education cohort members with high mortality risk prior to the survey dates has affected risk estimates.

Several studies have reported an association between various socioeconomic measures and symptoms of respiratory disease or lung function $[9,10]$. In a study of male nonsmokers the difference in forced expiratory volume in one second (FEV1) between the highest and lowest social class based on income and education was $400 \mathrm{~mL}$ [11]. Similar results were found by the authors in a previous study on subjects from the CCHS, which is part of the present study population. In that study, the smoking adjusted difference between the highest and lowest social group also based on income and education was $400 \mathrm{~mL}$ for males and 259 for females. This difference in lung function was reflected in a three-fold higher risk of admission to hospital for COPD [4]. In a well-designed Norwegian study, the odds ratio of COPD in primary versus university educated was 2.9 (1.3-6.5) after adjustment for occupational and smoking exposure [12]. The present study extends this association to mortality data.

The different measures of social position are closely correlated, but in theory each measure also has unique advantages. Employment grades reflect structural factors as well as exposure and job-related psychosocial factors. Income directly reflects material conditions, and housing conditions also reflect factors that could have direct effect on respiratory morbidity, i.e. humidity, crowding, and indoor pollutants. Education, more than other measures tends to precede disease. Educational attainment also reflects cultural aspects, such as tools for understanding and implementing health advice, and is probably more closely related to parental social placement and thus in uteri and childhood exposures.

Low household income has also been shown to be associated with COPD independent of smoking in both males and females in several studies [13, 14]. In a Canadian study, household income was related to self-reported COPD but more strongly in males than in females [15]. In the present study, income, both household and personal, was associated with respiratory mortality in males only and the association was seen across the whole spectre of income. Assuming that the material conditions associated with a given income are the same for males and females, the findings reported here question whether income in this context merely represents material conditions or also reflects other aspects associated with social position.

Some of the social gradient in respiratory diseases may be caused by occupational exposures depending on the spectre of occupational exposure in the population under study. Females generally do not hold jobs with major exposure to dusts and fumes that could potentially cause respiratory disease, yet social differences in lung diseases are found in both sexes [12]. A recent paper on the Whitehall II study showed that without adjustment for smoking self-reported incidence of chronic bronchitis was strongly associated with employment grade in males but not significantly in females [16]. In the present study, employment grade was associated with respiratory mortality in males only. Occupational exposure to dusts and fumes is limited in the area from which this study population originates, and is not likely to explain the association between employment grade and respiratory health.

Poor housing conditions, home dampness with increased house dust mites and gas-stove usage are associated with respiratory symptoms and lower social status. Household crowding has been found to cause increased incidence of respiratory infections, but whether this is associated with development of COPD in adulthood is unsettled. In a British study, people in areas of bad housing were found to report more respiratory symptoms, and flats were found to be worse than houses [17]. A Danish study focusing on housing found that smoking-adjusted FEV1 was reduced by $10 \mathrm{~mL} \cdot \mathrm{yr}$ of living $^{-1}$ without central heating [18]. However, these results could be caused by the correlation between housing and other measures of social grade. In the present study, the number of persons per room was associated with respiratory mortality in males, but not in females, and the use of central heating was 
not associated with mortality from respiratory disease after adjustment for other socioeconomic measures. Again, since the findings were not similar in males and females, the authors find it most likely that crowding and central heating do not directly affect lung health, but represent an underlying social reality.

Interestingly, the protective effect of cohabitation, which is perceived as a personal resource, was only seen in males. Being single or married is an indirect measure of various factors strongly affecting an individual's well-being, quality of social support, and health-related habits. That cohabitation is so strongly associated with mortality from respiratory disease in males is surprising. The authors do not know of studies showing that emotional support protects against development of respiratory disease.

Comparison of health differentials among females and males may provide useful insights into their causes. The social gradient in a females's health is particularly sensitive to how the inequality is defined. Social variation in morbidity in females is often found to be less than that of males $[19,20]$. Some studies have indicated that when a females's social position is classified according to the occupation of male and partner, male and female health gradients are more similar $[21,22]$. However, as pointed out, the various indices of social position also carry specific information and thus cannot be interchanged freely. The question of whether apparently smaller health gradients in females are due to imprecise measurement or represent real findings remains unsettled. It is possible that if there was a measure that gave a better guide to living and working circumstances throughout life, no sex differences would emerge. Certainly, if income, housing, and employment grade were merely indicators of material conditions and physical exposure, a priori expectations would be that there should be little or no differences between males and females.

Potential explanations of the social gradient in respiratory mortality include indirect selection, i.e. that factors predictive of ill health also predict future social position, e.g. parental social position. It is possible that the major determinant of adult social differences in lung disease is early childhood exposures. In the authors' previous study based on the CCHS, it was found that the difference in FEV1 between high and low social groups was not age-dependent, indicating that the exposures causing the social gradient have mostly already taken place early in life [4]. In the 1946 birth cohort of the British Medical Research Council, peak expiratory flow was associated with poor environment at the age of 2 yrs [23]. BARKER and co-workers [24-28] have shown that lower birth weight was associated with childhood respiratory disease and both were associated with adult lung function. Intrauterine influences, which retard foetal weight gain, may irrecoverably constrain the growth of the airways, and airways disease in childhood known to be associated with social conditions is undoubtedly also of importance in determining the incidence of COPD in adults. If parental social position, and thus early childhood exposure, was related strongly only to educational attainment in females, and in males also to income, housing and employment grade, this could explain the sex differences in the present study. Unfortunately, information on childhood circumstances or parental social situation were unavailable in the present study.

A shortcoming of the study is the lack of adjustment for changes in risk factors during follow-up. Socioeconomic factors, in particular education, are likely to remain stable but smoking habits may have changed and more so in the better educated [29]. Between 5-15\% of smokers quit between examinations with a 5-10-yr interval [30]. Given the natural history of chronic obstructive pulmonary disease, smoking cessation in subjects with established chronic obstructive pulmonary disease will have limited impact on mortality. In addition, analyses of never- and exsmokers, and analyses with limited duration of follow-up gave similar results. Thus, changes in smoking habits after study inclusion are not likely to explain the results. In conclusion, this study shows that a heavy smoker with the lowest level of education will have $>15$ times the risk of dying from respiratory disease compared with a nonsmoker with a high level of education. In these years, an increasing social gradient in smoking habits is seen that will increase the social gap in morbidity. Social position is a potentially avoidable cause of respiratory disease and further research is needed to explain the excess risk in the socioeconomically disadvantaged.

Acknowledgements. The authors are grateful for the help received from the Centre for Research in Health \& Social Statistics, Copenhagen, Denmark, in establishing the database.

\section{References}

1. Fein $\mathrm{O}$. The influence of social class on health status: American and British research on health inequalities. $J$ Gen Intern Med 1995; 10: 577-586.

2. Marmot MG, Shipley MJ, Rose G. Inequalities in death specific explanations of a general pattern? Lancet 1984; i: 1003-1006.

3. Turrell G, Mathers C. Socioeconomic inequalities in allcause and specific-cause mortality in Australia: 1985-1987 and 1995-1997. Int J Epidemiol 1999; 29: 231-239.

4. Prescott E, Lange P, Vestbo $\mathbf{J}$ and the Copenhagen City Heart Study Group. Socioeconomic status, lung function and admission to hospital for COPD. Eur Respir J 1999; 13: 1109-1114.

5. Appleyard M, Hansen AT, Schnohr P, Jensen G, Nyboe J. The Copenhagen City Heart Study. A book of tables with data from the first examination (1976-78) and a 5-year follow-up (1981-83). Scand J Soc Med 1989; 170: 1-160.

6. Hagerup L, Schroll M, Hollnagel H, Agner E, Larsen S. The Glostrup Population Studies. Collection of epidemiological tables. Reference values for use in cardiovascular population studies. Scand J Soc Med Suppl 1981; 20: 5-112.

7. Grambsch PM, Thernau TM. Proportional hazards tests and diagnostics based on weighted residuals. Biometrika 2001; 81: 515-526.

8. Martikainen P, Valkonen T. Bias related to the exclusion of the economically inactive in studies on social class differences in mortality. Int J Epidemiol 1999; 28: 899-904.

9. Trinder PM, Croft PR, Lewis M. Social class, smoking and the severity of respiratory symptoms in the general population. J Epidemiol Commun Health 2000; 54: 340-343.

10. Prescott E, Vestbo J. Socioeconomic status and chronic obstructive pulmonary disease. Thorax 1999; 54: 737-741.

11. Stebbings JHJ. Chronic respiratory disease among nonsmokers in Hagerstown, Maryland III. Social class and chronic respiratory disease. Environ Res 1971; 4: 213-232.

12. Bakke PS, Hanoa R, Gulsvik A. Educational level and obstructive lung disease given smoking habits and occupational airborne exposure: A Norwegian community study. Am J Epidemiol 1995; 141: 1080-1088.

13. Whittemore AS, Perlin SA, DiCiccio Y. Chronic obstructive pulmonary disease in lifelong nonsmokers: results from NHANES. Am J Public Health 1995; 85: 702-706.

14. Prescott E. Tobacco-related diseases: The role of gender. Dan Med Bull 2000; 47: 115-131.

15. Chen Y, Breithaupt K, Muhajarine N. Occurrence of chronic obstructive pulmonary disease among Canadians and sexrelated risk factors. J Clin Epidemiol 2000; 53: 755-761.

16. Marmot M, Shipley M, Brunner E, Hemingway H. Relative 
contribution of early life and adult socioeconomic factors to adult morbidity in the Whitehall II study. $J$ Epidemiol Commun Health 2001; 55: 301-307.

17. McCarthy P, Byrne D, Harrisson S, et al. Respiratory conditions: effects of housing and other factors. J Epidemiol Commun Health 1985; 39: 15-19.

18. Rasmussen FV, Borchsenius L, Winslew JB. Associations between housing conditions, smoking habits and ventilatory function in men with clean jobs. Scand J Respir Dis 1978; 59: 264-276.

19. Stronks K, van de Mheen H, van den Bos J, Mackenbach JP. Smaller socioeconomic inequalities in health among women: the role of employment status. Int J Epidemiol 1995; 24: 559568.

20. Koskinen S, Martelin T. Why are socioeconomic mortality differences smaller among women than among men? Soc Sci Med 1994; 38: 1385-1396.

21. Moser KA, Pugh HS, Goldblatt PO. Inequalities in women's health - looking at mortality differentials using an alternative approach. BMJ 1988; 296: 1221-1224.

22. Sacker A, Firth D, Fitzpatrick R, Lynch K, Bartley M. Comparing health inequality in men and women: prospective study of mortality 1986-96. BMJ 2000; 320: 13031307.

23. Britten N, Davies JMC, Colley JRT. Early respiratory experience and subsequent cough and peak expiratory flow rate in 36 year old men and women. BMJ 1987; 294: 13171320.

24. Stein CE, Kumaran K, Fall CH, Shaheen SO, Osmond C, Barker DJ. Relation of fetal growth to adult lung function in south India. Thorax 1997; 52: 895-899.

25. Shaheen SO, Barker DJ, Holgate ST. Do lower respiratory tract infections in early childhood cause chronic obstructive pulmonary disease? Am J Respir Crit Care Med 1995; 151: $1649-1652$.

26. Shaheen SO, Barker DJ, Shiell AW, Crocker FJ, Wield GA, Holgate ST. The relationship between pneumonia in early childhood and impaired lung function in late adult life. Am J Respir Crit Care Med 1994; 149: 616-619.

27. Barker DJ, Godfrey KM, Fall C, Osmond C, Winter PD, Shaheen SO. Relation of birth weight and childhood respiratory infection to adult lung function and death from chronic obstructive airways disease. BMJ 1991; 303: 671-675.

28. Barker DJ, Osmond C. Childhood respiratory infection and adult chronic bronchitis in England and Wales. BMJ 1986; 293: 1271-1275.

29. Osler M, Prescott E. Psychosocial, behavioural, and health determinants of successful smoking cessation: a longitudinal study of Danish adults. Tobacco Control 1998; 7: 262-267.

30. Osler M, Prescott E, Godtfredsen N, Hein HO, Schnohr P. Gender and determinants of smoking cessation. A longitudinal study. Prev Med 1999; 29: 57-62. 